\title{
Cross-Cultural Studies of Structural and Dynamic Features Of Learning Experiences among Russian and Chinese Teenagers
}

\author{
Liliya R. Fachrutdinova*1, Timur N. Sabirov ${ }^{2}$ \\ ${ }^{1,2}$ Kazan Federal University, Institute of Psychology and Education
}

*Email: liliarf@mail.ru

\section{Received: 21st October 2017 Accepted: 16th November 2017, Published: 31st December 2017}

\begin{abstract}
The modern educational space is characterized by the tendency to unification, the bringing to uniform standards throughout the world, the spread throughout the world of a single type of training developed in the Western world countries. This study is aimed at adaptation learning to the globalization processes in the education system using the examples of Russia and China, which are great countries in terms of their cultural heritage and traditions, including the field of education. We will consider the ways the Chinese and Russian teenagers experience the learning process in the context of education globalization through the study of educational activity subjective plan peculiarities among schoolchildren.

The purpose of our study is to examine the features of the structural and dynamic organization of learning experience among the adolescents in Russia and China. The leading approaches to the study of the problem are cultural-historical, system-structural and subjectactivity one developed by outstanding psychologists of Russia (L.S. Vygotsky, S.L. Rubinshtein, B.F. Lomov, etc.). The results of the study showed that the number and the strength of the interconnections between the characteristics of learning activity experience among Russian teenagers is much more qualitative than that of Chinese teenagers. The number and the strength of interconnections is much smaller and weaker among Chinese adolescents. For Russian students a school day is a single, holistic event on a subjective level where all subjects and lessons, regardless of content, are presented to them as the part of one educational process, and the taught subjects taught are related and reinforce each other (synergistic effect). Russian adolescents perceive a school day as a holistic phenomenon. Chinese teenagers regard a school day as something split into parts, and they do not see the interrelationships between lessons on a subjective level, and often lessons seem in the relations of antagonism.
\end{abstract}

Keywords: Experiencing, Consciousness, Space-Time and Information-Energy Characteristics of Experiencing, Cross-cultural Studies, Learning Activities, Russian and Chinese Teenager Psychology

\section{Introduction}

The research problem is related with the necessity to conduct cross-cultural studies of the internal, subjective aspect of educational activity in the conditions of the educational process of Russia and China. The structural-dynamic feature of the educational activity experience was studied among Russian and Chinese adolescents.

We have studied the space-time and informationenergy characteristics of learning experience during a school day - Monday. These characteristics were studied at the beginning, in the middle and at the end of the lesson, at the beginning, in the middle and at the end of a school day, that is, during the first, the third and the fifth lesson. Further, a comparative analysis of the structural and dynamic characteristics of learning activity experience was performed during a school day among Russian and Chinese students.

The main issue that has been solved in the study is about the features of the educational process subjective plan for adolescents in Russia and China, which will be manifested through the space-time and informationenergy characteristics of learning activity experience.

We relied on the presentation by L.S. Vygotsky about the experiencing as an internal plan for the social situation of development. In our work, the situation of the educational process in the conditions of the school is presented as a social situation. According to L.S. Vygotsky, experience is an internal, subjective plan for the social situation of development. We examined the subjective plan for the educational activities of Russian and Chinese adolescents. The cultural and historical concept by L.S. Vygotsky allows us to consider the reality of the cultural and historical environment influence on the particularities of material learning during lessons (Vygotsky, 2000). The representations about the nature, the structure of experience were developed by us in the doctoral dissertation (Fakhrutdinova 2012). The structure of the experience includes energy, space, time and information characteristics (Fakhrutdinova, 2009, 2010, 2012). Through these characteristics, we study the phenomenon of adolescent experiencing in the learning process.

The purpose of the study: the study of the structural and dynamic organization features concerning the ex- 
perience of educational activities by the adolescents in Russia and China.

Objectives of the study:

1. To conduct the theoretical analysis of the research problem.

2. To select psychological research tools and to organize research in Russian and Chinese schools.

3. To study the space-time and information-energy characteristics of learning activity experience at the beginning, middle and the end of a lesson at the first, the third and the fifth lessons during the school day (Monday).

4. To conduct the comparative analysis of the obtained results.

In order to conduct the study, we applied the questionnaire by L.R. Fahrutdinova "Degree of experience", which allows you to study the spatial, temporal, energy and information characteristics of experience in classroom lessons at schools easily and quickly.

The obtained results will allow developing the theory of experience created by L.R. Fakhrutdinova (2012), the ideas by L.S. Vygotsky on the cultural and historical concept of a person's psyche development (2000), the cross-cultural psychology to identify interethnic differences of people, pedagogical psychology - the psychology of learning, the age psychology of adolescents. Earlier, we studied the features of the experience during the listening to a melody, as well as the experience of educational activities of students at pedagogical universities of Russia and China. The differences in the indices of space-time and information-energy characteristics of Russian and Chinese adolescent experience were studied. The cross-cultural studies of the structural and dynamic characteristics of the educational activity experience among the adolescents in Russia and China were conducted for the first time. Previously, the structural and dynamic features of Russian schoolchildren experience from the second to the eleventh grade were studied and the cycles of learning experience were revealed (Fakhrutdinova L.R. 2012). In this paper other statistical methods of data processing were applied and for the first time the structural and the dynamic organization of Russian and Chinese pupil experience was compared.

\section{Materials and Methods}

40 schoolchildren of Russian Federation schools, as well as 50 pupils from the schools of the People's Republic of China at the age of 11-12 years (boys and girls) took part in the study. Thus, 90 Russian and Chinese teenagers participated in the experiment.

To study the experiencing indicators we used the "experiencing thermometer" (Vygotsky, L.S., 2000). This checklist consists of four scales: "Energy characteristics", "spatial characteristics", "time response" and "Information Data".
Scale "Energy characteristic" reflects the intensity, strength, brightness, power, experience of the subject. High scores on this scale indicate that the subject is experiencing very intense, energy-charged experiences that give a person a very strong inspiration, energy, power, lifting, shaking the very foundations of his being or experience high intensity, which completely absorb all the forces of the subject, his experience in fact, withdraw all the energy from the rest of his mental life. Low rates reflect the week experiences of very low intensity, the lowest figures reflect that the event actually happening does not cause any feelings in the subject.

Scale "spatial characteristics" shows the volume, breadth and depth of coverage of the experiences of the inner life of man. High values on this scale mean that the experience almost completely captures the subject, a high level of being "occupied" by the experience. If we compare with the fire in the room: the fire engulfed almost the entire room. Low values of this scale means that the subject gives experience a small place in his inner life. There are much more other more important internal events in his inner life.

Scale "time characteristics" refers to the effect this experience has on the internal time. Higher values indicate that the experience causes the subjective feeling of time speeding up, the saturation of the time by events. Time passes quickly and quietly. Very high temporal characteristics are associated with the feeling that the subject simply can't keep up with the times, can't control the events which appear to be too quickly. The time sequence is broken, he is lost in this dance of events. Low values indicate that the experienced events produce the feeling of time slowing down, it is felt to be slow, to flow painfully and slowly. But at the same time, this figure may mean dropping out from the time flow, detachment from what is happening, contemplation.

Scale "Information response" shows the importance of this experience for the subject, the degree of personal involvement in what is happening, how the experience changes him, in what degree it gives knowledge. The higher values reflect very high importance of experience for the subject, its high information saturation. The subject feels how this experience changes him. Low rates mean that the experience gives the subject a little in terms of life experience, knowledge and information. It is irrelevant to the subject.

Each thermometer has a grading from 1 to 5 and corresponds to one of four of the aforementioned characteristics. For example, a thermometer scale "Energy characteristics." The students evaluate the energy characteristic of the experience of what is happening to them in the classroom and note on the scale: 
1. The strength, intensity, energy, my experiences

$$
\text { 1-----2-----3-----4-----5 }
$$

This test has the advantage of the operational capabilities of the application, for example to diagnose the dynamics of the experience in the classroom (Fakhrutdinova L.P., 2010).

Study procedure. The experience of adolescents was studied during the school day at the first, the third and the fifth lessons. At each lesson, which lasted 45 minutes for Chinese and Russian students, energy, space, time and information characteristics at the beginning, the middle and the end of the lesson were measured. The measurements were performed using the questionnaire by L.R. Fakhrutdinova "Degree of experience". The obtained data were analyzed using the statistical package SPSS 13.0, Statistic 6.0.

\section{Results}

The obtained data were subjected to the correlation analysis using the Spearman method. The results of the research showed the presence of reliable relations between the characteristics of the experience among Chinese and Russian schoolchildren. The difference was manifested in the number and the quality of the relations (Figure 1). At that the differences were very noticeable. Among 1260 possible links (36 indicators during the school day for each schoolchild), 48 correlation links were found in China, and 474 links in Russia, which is almost 10 times more.

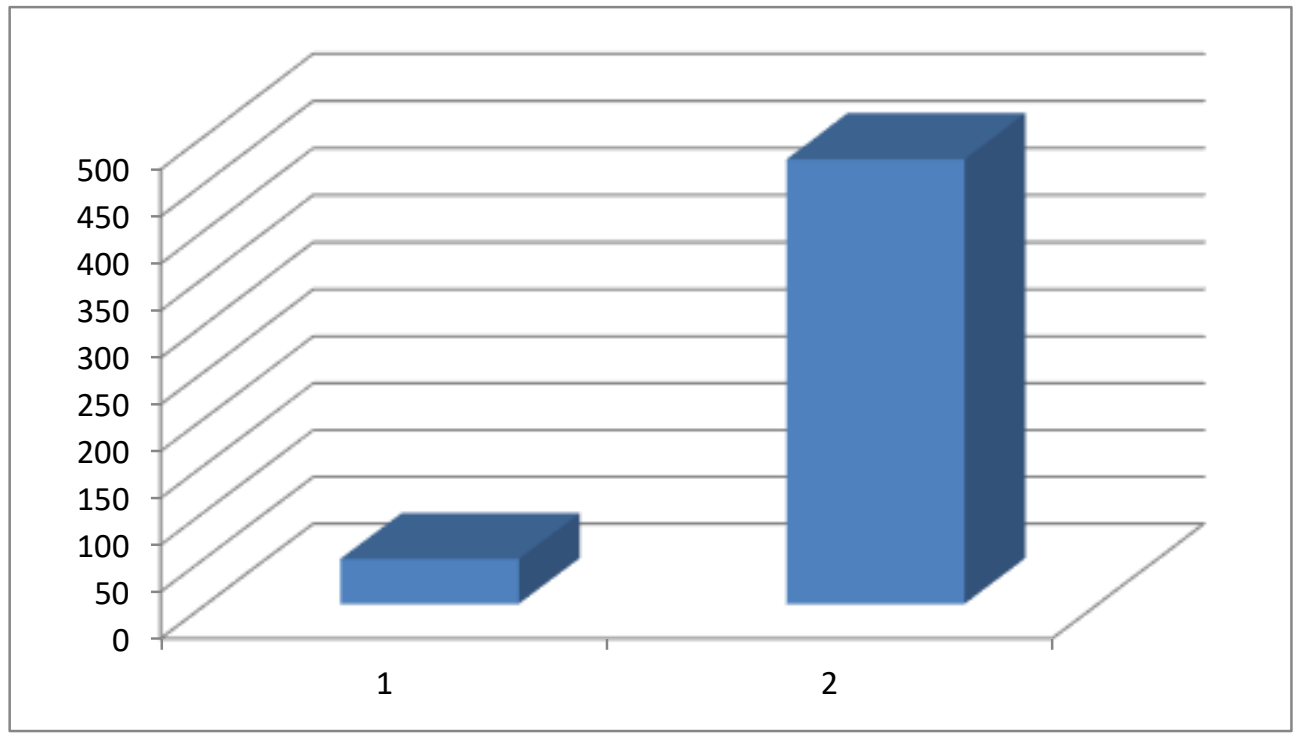

Figure 1. Correlation Relations Between the Space-Time and Information Characteristics of Learning Activity Experiences in a Classroom During the School Day (Monday) among Chinese and Russian teenagers. Designations:

1 - The first column shows the number of correlation links between the characteristics of experience among Chinese school children.

2 - The second column shows the number of correlation links between the characteristics of experience among Chinese school children.

Moreover, it was revealed that there was the increase in the links between characteristics during one lesson and their reduction between different lessons both for Chinese and Russian schoolchildren, which shows the unity of the learning process at one lesson. But they also revealed the existence of links between the indicators of experience during certain lessons - which already characterizes the school as a single space of the educational process in the subjective world of adolescents.

Russian schoolchildren had different number of links between the characteristics of experience, both at separate lessons and between different lessons as compared to Chinese schoolchildren not only in quantity but also in quality: the amount of correlations between Russian schoolchildren reached 0.852 at $p=0.0001$, but kept at least 0,403 at $\mathrm{p}=0.01$. On the average, the correlation value was 0,679 . Besides, all relations were positive ones.

While the correlation value did not exceed 0,457 at $\mathrm{p}=$ 0.001 among the Chinese students, the lowest values reached 0,295 at $p=0.038$. Besides 9 links out of 48 ones were negative, which indicates the disharmonious, contradictory relationship between separate lessons. At the subjective level, one subject suppressed the perception of the other one.

These studies showed that the correlation between the characteristics of experience among Russian schoolchildren is much more larger and stronger. Besides all of them are positive ones. The obtained results may indicate that in Russian schools the educational activity 
is a more integrated, unified phenomenon among the adolescents at the age of 11-12. The subjective plan of educational activity of adolescents in Russia can be much more developed. The teaching activity among the adolescents in the subjective aspect during a school day in Russia is presented as a single, uninterrupted process, which can indicate a high professional level of Russian pedagogical school in comparison with the Chinese pedagogical school. The educational process is built in such a way that a school day is presented as something whole for Russian schoolchildren. This integrity in the subjective aspect of a school day can make it possible to increase the effectiveness of the educational process by an order, since synergetic effects are included here. A small number of connections between the characteristics of the experience of learning activity among Chinese adolescents shows the dissociation of individual lessons, their low synergies, a low level of interrelation between the way of different lessons teaching, which does not lead to the development of a school day as a holistic phenomenon of the Chinese school educational space.

\section{Conclusions}

1. The theoretical analysis of the problem was carried out, which showed that the crosscultural study of the structural and dynamic features of Chinese and Russian adolescents was conducted for the first time and is relevant for the study of globalization processes in education.

2. The results of the study showed the structural and dynamic features of the educational activities of adolescents in Russia and China. Qualitative and quantitative differences in the structural relationships between the components of the learning experiences of adolescents were revealed.

3. The number and the strength of the links between the characteristics of the educational process during the school day among Russian teenagers exceeded the corresponding links among Chinese teenagers by an order.

\section{Summary}

Thus, the study showed that for Russian schoolchildren the learning process during the school day represents a single, holistic phenomenon of a teenager's subjective life, all the subject lessons are presented as the part of a single educational space, while among Chinese teenagers the existence of interrelations between the subjects for their subjective perception of education at school is much weaker. These studies showed that Russian school is endowed with a high ability to use the power of some subjects to acquire the knowledge of other subjects and Russian schoolchildren consider the school as a single educational space.

\section{Acknowledgements}

The work is performed according to the Russian Government Program of Competitive Growth of Kazan Federal University.

The article is prepared under the financial support of RFFI.

Project 17-29-02092 ofi_m

The complex model of risk evaluation in social-cultural environment of school.

\section{References}

Vygotsky, L.S. Psychology / L.S. Vygotsky. (2000). M.: April news: Eksmo-Press.

Rubinstein S. L. Fundamentals of General psychology. So-2. (1989). - M.: Pedagogy/

Fachrutdinova L.P. Theory experiences.(2009) - Kazan, KGU publishing house. Fachrutdinova.L.R. On the Phenomenon of "Experience". - "Journal of Russian and East European Psycology.March-April.2010/ VOL. - 48, NO.2. - R. 31-47.

Fachrutdinova L.R., Nugmanova D.R. Dynamics of psychological crisis experience with psychological consulting by gestalt therapy methods".http://www.scopus.com/record/display.url?eid=2s2.0-84929452489\&origin=resultslist\&sort=plf-

$\mathrm{f} \& \mathrm{src}=\mathrm{s} \& \mathrm{st} 1=$ Dynamics + of + psychologi cal+crisis+experience+with+psychological+consulting+by+gestalt+therapy+methods \&st $2=\& s i$ d=B2BD792E6DB340CA79F41EBB1BC46667.FZg2 OD-

cJC9ArCe8WOZPvA\%3a340\&sot=b\&sdt=b\&sl=115\& $\mathrm{s}=$ TITLE-ABS-KEY\%28Dynamics+of+psychologi-

cal+crisis+experience+with+psychologi-

cal+consulting+by+gestalt+therapy+methods $\% 29 \&$ relp os $=0 \&$ relpos $=0 \&$ citeCnt $=1 \&$ searchTerm $=$ TITLE-

ABS-KEY\%28Dynamics+of+psychologi-

cal+crisis+experience+with+psychologi-

cal+consulting+by+gestalt+therapy+methods $\% 29$ from 10.09.2015.

Fakhrutdinova L.R., Sabirov T.N. Experience of educational activity and intellectual abilities of junior schoolchildren of the People's Republic of China / / Natural-scientific approach in modern psychology / Ed. in charge V.A. The drummers. Moscow: Publishing house "Institute of Psychology of the Russian Academy of Sciences". - 2014. - pp. 796-800.

Sabirov T.N., Fakhrutdinova L.R. Mental state and experience of educational activity of senior pupils // Procedures and methods of experimental psychological research / Ed. in charge V.A. The drummers. Moscow: The publishing house "Institute of Psychology of the Russian Academy of Sciences", 2016. - 950 p. - pp. 887-892.

Fachrutdinova L.R., Sabirov T.N. Mental states and experiences of educational activity of senior/Psychology of psychological state. - Issue 11. Kazan, 2017. - pp. 221-226. 